\title{
Academic performance, externalizing disorders and depression: 26,000 adolescents followed into adulthood
}

\author{
Alma Sörberg Wallin ${ }^{1}\left[\right.$ - Ilona Koupil ${ }^{1,2} \cdot$ Jan-Eric Gustafsson ${ }^{3} \cdot$ Stanley Zammit ${ }^{4,5} \cdot$ Peter Allebeck $^{1}$. \\ Daniel Falkstedt ${ }^{1}$
}

Received: 8 July 2018 / Accepted: 4 February 2019 / Published online: 19 February 2019

(C) The Author(s) 2019

\begin{abstract}
Background The incidence of major depression among adults has been shown to be socially differentiated, and there are reasons to seek explanations for this before adulthood. In this cohort study, we examined whether academic performance in adolescence predicts depression in adulthood, and the extent to which externalizing disorders explain this association.

Methods We followed 26,766 Swedish women and men born 1967-1982 from the last year of compulsory school, at age about 16, up to 48 years of age. We investigated the association between grade point average (GPA, standardized by gender) and first diagnosis of depression in national registers of in- or out-patient psychiatric care. We used Cox proportional hazards models, adjusting for lifetime externalizing diagnoses and potential confounders including childhood socioeconomic position and IQ.

Results During follow-up, $7.0 \%$ of the women and $4.4 \%$ of the men were diagnosed with depression. A GPA in the lowest quartile, compared with the highest, was associated with an increased risk in both women (hazard ratio 95\% confidence interval 1.7, 1.3-2.1) and men (2.9, 2.2-3.9) in models controlling for potential confounders. Additional control for externalizing disorders attenuated the associations, particularly in women.

Conclusions The findings suggest that poor academic performance is associated with depression in young adulthood and that the association is partly explained by externalizing disorders. Our results indicate the importance of early detection and management of externalizing disorders among children and adolescents.
\end{abstract}

Keywords Academic performance $\cdot$ Depression $\cdot$ Externalizing disorders $\cdot$ Cohort study $\cdot$ Life course studies

Electronic supplementary material The online version of this article (https://doi.org/10.1007/s00127-019-01668-z) contains supplementary material, which is available to authorized users.

Alma Sörberg Wallin

alma.sorberg.wallin@ki.se

1 Department of Public Health Sciences, Karolinska Institutet, Solnavägen 1E, 13164 Stockholm, Sweden

2 Department of Public Health Sciences, Stockholm University, Stockholm, Sweden

3 Department of Education and Special Education, University of Gothenburg, Gothenburg, Sweden

4 Centre for Academic Mental Health, Population Health Sciences, Bristol Medical School, University of Bristol, Bristol, UK

5 Division of Psychological Medicine and Clinical Neurosciences, MRC Centre for Neuropsychiatric Genetics and Genomics, Cardiff University, Cardiff, UK

\section{Introduction}

Epidemiological studies have shown that poorer academic performance in school is associated with a higher risk of psychiatric illness in adulthood [1-3], including major depression [1]. In this context, differences in socio-economic background do not seem to be a confounding factor [1-3]. Lower educational levels and social positions in adulthood are also associated with a higher risk of depression [4], but since the school grades signal future risk, those associations are at least partly explained by factors present during the school years. However, previous studies have had limited statistical power [1] or examined mental disorders more broadly rather than depression [2, 3]. Furthermore, little is known about any other underlying factors that might contribute to the association.

Internalizing and externalizing psychological symptoms have been extensively studied as possible risk factors for poor 
academic performance. Several studies on developmental trajectories have been aimed at disentangling the associations between these psychological symptoms and academic performance over time. Most (but not all, e.g. [5]) conclude that externalizing problems appear to affect performance adversely whereas the evidence of a causal effect of internalizing problems on academic performance is weak [6-9]. Furthermore, a recent systematic review on educational attainment showed that externalizing disorders seem to account for associations between internalizing disorders (including depression) and school dropout in adolescents [10]. A previous systematic review with a broader scope [11] and a subsequent study of 8000 Norwegian adolescents in the Young HUNT cohort [12] came to a similar conclusion that externalizing problems have a more adverse impact than internalizing problems on academic performance and attainment.

Since externalizing disorders also constitute a risk factor for adult depression [13], they might be involved in the association between poor academic performance and depression. In line with this, a register-based study following 19,000 Swedish women and men up to age 30 showed that lower grade point average (GPA) was associated with depression primarily among those with a history of diagnosed externalizing disorders [1]. However, the estimates were uncertain because of the low number of cases available. Moreover, the analyses were not stratified by gender, even though the risk of depression is higher in women [14] and the circumstances contributing to depression might differ between genders, for example concerning the impact of social status on depression risk [15]. There are also considerable differences between women and men in the rate and type of diagnosed externalizing disorders [16], giving further indication that a stratification by gender might be important.

\section{Aim}

We set out to investigate the association between academic performance in adolescence and subsequent risk of depression among Swedish women and men, until they were 33-48 years old. We wanted to find out whether externalizing disorders might explain the association, and we also adjusted for other potentially important information about the participants in the analyses: socioeconomic position (SEP) in childhood and immigrant background [17], diagnoses in psychiatric care, and intelligence quotient (IQ) at 13 years of age.

\section{Methods}

\section{Study population}

Since the 1960s, systematic data collections have been performed at the University of Gothenburg within the project
Evaluation Through Follow-up (ETF). The purpose is to evaluate the school system and to provide data for longitudinal studies on educational and occupational careers. Statistics Sweden, the administrative agency responsible for official and governmental statistics in Sweden, linked the data to several national databases. About $10 \%$ of the population was sampled in each of the cohorts examined, except for the 1977 cohort in which only $5 \%$ was sampled. The number of participants and the information collected have varied between cohorts for practical and financial reasons. More information about the project is found on the ETF website [18]. For the current study, the following four birth cohorts which had similar information available were included: pupils born in $1967(n=7842), 1972(n=7740), 1977(n=3861)$ and $1982(n=7323)$. We excluded participants who immigrated to Sweden after the 4th school year because academic performance and IQ test performance in newly immigrated students are likely to be affected by unfamiliarity with the language. We also excluded participants with an in-patient psychiatric diagnosis before graduation, and also those with a lifetime diagnosis of bipolar disorder or schizophrenia in the in- and out-patient registers (described below), partly to reduce misclassification and partly because people who develop psychosis might have altered neurodevelopment in adolescence [19] (the ICD codes used are provided in Supplementary Table A). Further, we excluded participants with missing data on any of the included variables. The study was approved by the Regional Ethics Board in Stockholm, with reference number 2016/631-32.

\section{Academic performance}

School grades from the 9th school year, i.e. the final year of compulsory education at approximately age 16, were extracted from the school register held by Statistics Sweden (for the cohort born in 1967, school grades were instead extracted from the ETF dataset). The subject grades were based on the students' overall performance on tests as well as knowledge demonstrated during the semester. School grades from the 9th school year were decisive for admission to upper secondary schools, so the incentives to perform well were strong.

One or more grades were missing for about $5 \%$ of the students, either because they had failed a subject or because they were exempted from it. If, in the present study, these students had been excluded from the analyses, this would have caused bias because they were the poorest performers among all the students, and participants who were later diagnosed with depression and externalizing disorders were overrepresented in this group. Therefore, the students for whom one, more, or all grades were missing were assigned the lowest possible grades. After that, we calculated the GPA according to previously used procedures [20] 
and standardized the grade score into a $z$ score (mean $=0$, $\mathrm{SD}=1$ ), separately for women and men for each cohort.

\section{Outcome: depression in psychiatric care}

Information on diagnosis of depression, either as a primary or contributing diagnosis, was obtained from the national inand out-patient registers, administered by the National Board of Health and Welfare. Primary diagnoses only were used in a sensitivity analysis (see below). In-patient data were available from 1973 to 2015, and out-patient data from 2001 to 2015, starting from when the participants in the four cohorts were aged 34, 29, 24 and 19, respectively. The ICD codes used were: 296.0, 300.4, 298.0 (ICD-8, 1973-1986); 296B, 298A, 300E, 311 (ICD-9, 1987-1996); F32-F33 (ICD-10, 1997 onwards).

\section{Covariates}

Information on socioeconomic position (SEP) in childhood was obtained from the National Censuses of 1980, 1985 and 1990 when the participants were at ages $8-13$. SEP was indicated by the father's occupation, classified into eight categories: (1) unskilled workers; (2) skilled workers; (3) assistant non-manual employees; (4) non-manual employees at intermediate level; (5) non-manual employees at higher level; (6) farmers; (7) self-employed; and (8) those with no occupation reported. Immigrant background was indicated if the participant or any of their parents had immigrated to Sweden, as registered in the national migration database. Information on any psychiatric diagnosis in parents as well as psychiatric diagnosis in the participants prior to graduation from compulsory school and two years thereafter was obtained from the National In-patient Register, using ICD codes: 290-315 (ICD-8, years as above); 290-319 (ICD-9); F00-F99 (ICD-10).

At the age of 13 , a test of cognitive ability was administered to all children by classroom teachers, according to written detailed instructions. The sum of three subtests (verbal ability: antonyms; spatial ability: metal folding; reasoning: number series tests), with a maximum of 120 points, constitutes a measure of global cognitive ability or IQ. The IQ test has been tested for validity against the Swedish conscription test of general cognitive ability with a correlation of 0.78 [21] as described in detail elsewhere [22, 23].

Information on externalizing disorders was obtained from the national patient registers, as above. Externalizing disorders comprise a wide range of diagnoses and there is emerging evidence of a shared aetiology and common genetic vulnerabilities among them [24, 25]. Some of these disorders have their onset more clearly rooted during childhood and early adolescence (for example attention deficit hyperactivity disorder [ADHD] and conduct disorders, and personality disorders, which often develop early in life but are rarely diagnosed before adulthood), whilst others, such as substance use, are more likely to emerge in adulthood. As the latter group could theoretically develop as a consequence of poor educational outcomes, we divided the externalizing disorders into two categories (diagnosis types with ICD-10 codes in parenthesis; see Supplementary Table B for all ICD codes including earlier versions): (1) childhood-onset and personality disorders (hyperkinetic and conduct disorders, F90-91; emotionally unstable/borderline and dissocial personality disorders, F60.2, F60.3), and (2) other externalizing disorders (mental and behavioural disorders due to psychoactive substance use, F10-19; abuse of nondependenceproducing substances, F55; habit and impulse disorders, F63). Diagnoses in the latter category were excluded if they occurred for the first time concurrently with or after a first diagnosis of depression (97 events) to minimize bias.

\section{Statistical analyses}

We examined the association between GPA (coded as quartiles based on $z$ scores, and also per standard-deviation (SD) decreases in the $z$ scores) and first diagnosis of depression using Cox proportional hazards regression. We introduced interaction terms to investigate statistical interactions of GPA with gender and cohort in the association with depression. We found no evidence of interaction effects by cohort $(p>.20)$, but an indication of interaction between gender and GPA $(p=.07)$. Thus, we pooled the four cohorts, but performed the analyses separately for women and men based on our interaction result and also because gender differences in the aetiology of depression have been observed [15]. The participants were followed from July 1st after graduation from the 9th school year (the year they turn 16 years old), up until December 31st 2015 (with their age ranging from 33 to 48 years), or date of first diagnosis of depression, emigration or death due to any cause, whichever came first. We checked for proportionality over time using scaled Schoenfelds residuals [26] and found no violation of the proportionality assumption. In the regression models, we adjusted for childhood SEP, immigration background, parents' psychiatric disorder, IQ at age 13, and lifetime externalizing disorders.

Several sensitivity analyses were carried out. First, we added a time lag of 10 years after graduation, to minimize the risk of reverse causality. Second, for the same reason, we excluded participants with any psychiatric diagnosis in the in-patient register up to 2 years after graduation. Third, we restricted the depression events to include only in-patient and only primary diagnoses of depression, respectively. Fourth, we repeated the analyses without any replacement of incomplete or missing grades GPA scores, and instead excluding 805 participants which such scores. 


\section{Results}

Of 31,737 participants in the four cohorts, 26,766 (84\%) met the inclusion criteria and were eligible for followup. Most of the exclusions were due to missing data on IQ $(n=3231,10 \%)$. The participants were followed up to the end of 2015, thus a follow-up time between 17 and 32 years. During this time, 1513 (5.7\%; 7.0\% of women and $4.4 \%$ of men) participants were diagnosed with depression for their first time in- or out-patient psychiatric care (Table 1). Externalizing disorders were clearly overrepresented in participants with a diagnosis of depression, especially of the childhood-onset and personality disorder kinds. These diagnoses occurred to the same extent in women and men (1.7\%). Of the specific diagnoses in this group, hyperkinetic disorders (F90 in the ICD-10) were the most prevalent in both genders, although more common in men than women (189 and 130 cases, respectively; Supplementary Table B). Overall, the potential confounders, including a lower mean IQ, disadvantageous childhood SEP, immigrant background, and having a parent with a psychiatric diagnosis, were consistently more common in participants with depression (Table 1) and in those with GPA scores in the lower quartiles (Table 2). Externalizing diagnoses in particular were more common in those with lower GPA scores (Table 2).

GPA at age 16 was associated with subsequent depression in both women and men (Table 3 ). In women, the increased risk of depression was concentrated to the lowest GPA quartile, whereas in men, it was more graded across the quartiles. However, a test of non-linearity suggested a non-linear association for both genders $(p<.001)$. In model $\mathrm{I}$, adjusting for cohort only, risk of depression was doubled
Table 1 Prevalence of GPA, IQ, externalizing disorders and control variables in women and men, in the total set of cohorts and in those with depression during follow-up

\begin{tabular}{|c|c|c|c|c|}
\hline & \multicolumn{2}{|l|}{ Total } & \multicolumn{2}{|c|}{ Depression } \\
\hline & $N /$ mean & $\% / S D$ & $N /$ mean & $\% / \mathrm{SD}$ \\
\hline Total & 26,766 & $(100)$ & 1513 & $(5.7)$ \\
\hline \multicolumn{5}{|l|}{ Women } \\
\hline$N(\%)$ & 13,058 & $(48.8)$ & 908 & $(60.0)$ \\
\hline Standardized GPA, mean (SD) & 0.00 & $(1.00)$ & -0.34 & $(1.08)$ \\
\hline Standardized IQ, mean (SD) & 0.00 & $(1.01)$ & -0.23 & $(1.06)$ \\
\hline Externalizing disorder & 551 & $(4.2)$ & 196 & $(21.6)$ \\
\hline Childhood-onset + PD, $N(\%)$ & 222 & $(1.7)$ & 135 & $(14.9)$ \\
\hline Substance use + impulse disorder ${ }^{\mathrm{a}}, N(\%)$ & 329 & $(2.5)$ & 61 & $(6.7)$ \\
\hline \multicolumn{5}{|l|}{ Childhood SEP } \\
\hline Manual occupation, $N(\%)$ & 4846 & $(37.1)$ & 339 & $(37.3)$ \\
\hline Non-manual occupation, $N(\%)$ & 5268 & $(40.3)$ & 324 & $(35.7)$ \\
\hline Other (mostly no occupation), $N(\%)$ & 2944 & $(22.6)$ & 245 & $(27.0)$ \\
\hline First or second generation immigrant, $N(\%)$ & 2542 & $(19.5)$ & 197 & $(21.7)$ \\
\hline Parents' psychiatric diagnosis, $N(\%)$ & 2469 & $(18.9)$ & 275 & $(30.3)$ \\
\hline \multicolumn{5}{|l|}{ Men } \\
\hline$N(\%)$ & 13,708 & $(51.2)$ & 605 & $(40.0)$ \\
\hline Standardized GPA, mean (SD) & 0.00 & $(1.00)$ & -0.39 & $(0.96)$ \\
\hline Standardized IQ, mean (SD) & 0.00 & $(0.98)$ & -0.23 & $(1.09)$ \\
\hline Externalizing disorder & 802 & (5.9) & 179 & $(29.6)$ \\
\hline Childhood-onset + PD, $N(\%)$ & 235 & $(1.7)$ & 109 & $(18.0)$ \\
\hline Substance use + impulse disorder ${ }^{\mathrm{a}}, N(\%)$ & 567 & $(4.1)$ & 70 & $(11.6)$ \\
\hline \multicolumn{5}{|l|}{ Childhood SEP ${ }^{\mathrm{b}}$} \\
\hline Manual occupation, $N(\%)$ & 5140 & $(37.5)$ & 228 & $(37.7)$ \\
\hline Non-manual occupation, $N(\%)$ & 5635 & $(41.1)$ & 216 & $(35.7)$ \\
\hline Other (mostly no occupation), $N(\%)$ & 2933 & $(21.4)$ & 161 & $(26.6)$ \\
\hline First or second generation immigrant, $N(\%)$ & 2674 & $(19.5)$ & 141 & $(23.3)$ \\
\hline Parents' psychiatric diagnosis, $N(\%)$ & 2600 & $(19.0)$ & 176 & $(29.1)$ \\
\hline
\end{tabular}

${ }^{a}$ Excluding substance use and impulse disorders diagnosed concurrently with or after a diagnosis of depression

${ }^{\mathrm{b}}$ Combined categories are used for illustration in this table; in the regression models, we use eight categories of childhood SEP 
Table 2 The distribution of potential explanatory factors across GPA quartiles

\begin{tabular}{|c|c|c|c|c|c|c|c|c|}
\hline & \multicolumn{8}{|c|}{ GPA quartiles } \\
\hline & \multicolumn{2}{|l|}{$1 \mathrm{st}$} & \multicolumn{2}{|l|}{ 2nd } & \multicolumn{2}{|l|}{3 rd } & \multicolumn{2}{|l|}{4 th } \\
\hline & $N /$ mean & $\% / \mathrm{SD}$ & $N /$ mean & $\% / \mathrm{SD}$ & $N /$ mean & $\% / \mathrm{SD}$ & $N /$ mean & $\% / \mathrm{SD}$ \\
\hline \multicolumn{9}{|l|}{ Women } \\
\hline Standardized IQ, mean (SD) & -0.80 & $(0.92)$ & -0.24 & $(0.81)$ & 0.21 & $(0.77)$ & 0.74 & $(0.72)$ \\
\hline Externalizing disorder, $N(\%)$ & 286 & $(9.4)$ & 110 & $(3.5)$ & 101 & $(2.8)$ & 54 & $(1.6)$ \\
\hline Childhood-onset + PD, $N(\%)$ & 120 & (3.9) & 43 & $(1.4)$ & 37 & $(1.0)$ & 22 & $(0.7)$ \\
\hline Substance use + impulse disorder ${ }^{\mathrm{a}}, N(\%)$ & 166 & $(5.4)$ & 67 & $(2.2)$ & 64 & $(1.8)$ & 32 & $(1.0)$ \\
\hline \multicolumn{9}{|l|}{ Childhood SEP $^{\mathrm{a}}$} \\
\hline Manual occupation, $N(\%)$ & 1484 & $(48.7)$ & 1340 & $(43.0)$ & 1245 & $(35.0)$ & 777 & $(23.3)$ \\
\hline Non-manual occupation, $N(\%)$ & 692 & $(22.7)$ & 1067 & $(34.3)$ & 1563 & $(44.0)$ & 1946 & $(58.3)$ \\
\hline Other (mostly no occupation), $N(\%)$ & 874 & $(28.7)$ & 708 & $(22.7)$ & 746 & $(21.0)$ & 616 & $(18.5)$ \\
\hline First or second generation immigrant, $N(\%)$ & 739 & $(24.2)$ & 617 & $(19.8)$ & 646 & $(18.2)$ & 540 & $(16.2)$ \\
\hline Parents' psychiatric diagnosis, $N(\%)$ & 756 & $(24.8)$ & 626 & $(20.1)$ & 629 & $(17.7)$ & 458 & $(13.7)$ \\
\hline \multicolumn{9}{|l|}{ Men } \\
\hline Standardized IQ, mean (SD) & -0.78 & $(0.93)$ & -0.19 & $(0.85)$ & 0.26 & $(0.79)$ & 0.80 & $(0.73)$ \\
\hline Externalizing disorder, $N(\%)$ & 459 & $(12.8)$ & 192 & $(5.2)$ & 87 & $(2.8)$ & 64 & $(1.9)$ \\
\hline Childhood-onset + PD, $N(\%)$ & 145 & $(4.0)$ & 45 & $(1.2)$ & 32 & $(1.0)$ & 13 & $(0.4)$ \\
\hline Substance use + impulse disorder ${ }^{\mathrm{a}}, N(\%)$ & 314 & $(8.7)$ & 147 & $(4.0)$ & 55 & $(1.8)$ & 51 & $(1.5)$ \\
\hline \multicolumn{9}{|l|}{ Childhood SEP $^{\mathrm{a}}$} \\
\hline Manual occupation, $N(\%)$ & 1759 & $(49.0)$ & 1535 & $(41.9)$ & 1060 & $(33.8)$ & 786 & $(23.7)$ \\
\hline Non-manual occupation, $N(\%)$ & 843 & $(23.5)$ & 1313 & $(35.8)$ & 1469 & $(46.9)$ & 2010 & $(60.6)$ \\
\hline Other (mostly no occupation), $N(\%)$ & 990 & $(27.6)$ & 818 & $(22.3)$ & 603 & $(19.3)$ & 522 & $(15.7)$ \\
\hline First or second generation immigrant, $N(\%)$ & 832 & $(23.2)$ & 714 & $(19.5)$ & 576 & $(18.4)$ & 552 & $(16.6)$ \\
\hline Parents' psychiatric diagnosis, $N(\%)$ & 909 & $(25.3)$ & 715 & $(19.5)$ & 516 & $(16.5)$ & 460 & $(13.9)$ \\
\hline
\end{tabular}

${ }^{a}$ Combined categories are used for illustration in this table; in the regression models, eight categories of childhood SEP are used

in women in the lowest GPA quartile and was nearly three times higher in men, compared with their counterparts in the highest GPA quartiles. Adding childhood SEP, immigration background, parents' psychiatric diagnosis, and childhood IQ to the model (model II) had a small attenuating effect on the association in women, but not in men. Adding a diagnosis of externalizing disorders to the model had a clear attenuating effect in women, in particular when adjusting for childhood-onset and personality disorders (model III; approximately $40 \%$ attenuation in calculations based on the $\log [\mathrm{HR}]$ ), and a smaller attenuating effect in men (approximately $20 \%$ attenuation). In comparison, adjusting for the externalizing disorders which typically develop in adulthood had less impact on the associations (model IV). In the full model adjusting for both types of externalizing disorders (model V), the association between poor academic performance and depression was additionally attenuated in men to more than a doubled risk in the lowest quartile compared with the highest. In women, there was no additional attenuation compared with model III, but only a slightly increased risk of $30 \%$ remained in the lowest quartile, and no increased risk in the other quartiles.
The sensitivity analyses yielded results in line with the main analyses, with marginally weaker associations in the analyses with a time lag (Supplementary Table C) or excluding participants with an early psychiatric diagnosis (Supplementary Table D). The associations were slightly weaker when the outcome was restricted to only primary diagnoses of depression (Supplementary Table E). The associations were slightly stronger in women but weaker in men in analyses of in-patient diagnoses only (Supplementary Table F), although with fewer cases the estimates are more uncertain. Excluding the participants who had a replaced GPA measure due to missing or incomplete grades yielded very similar results as the main analyses (Supplementary Table G).

\section{Discussion}

\section{Summary}

In this population of 26,000 Swedish women and men, lower grades at the end of compulsory school (at age 16) were associated with a higher risk of diagnosed depression in 


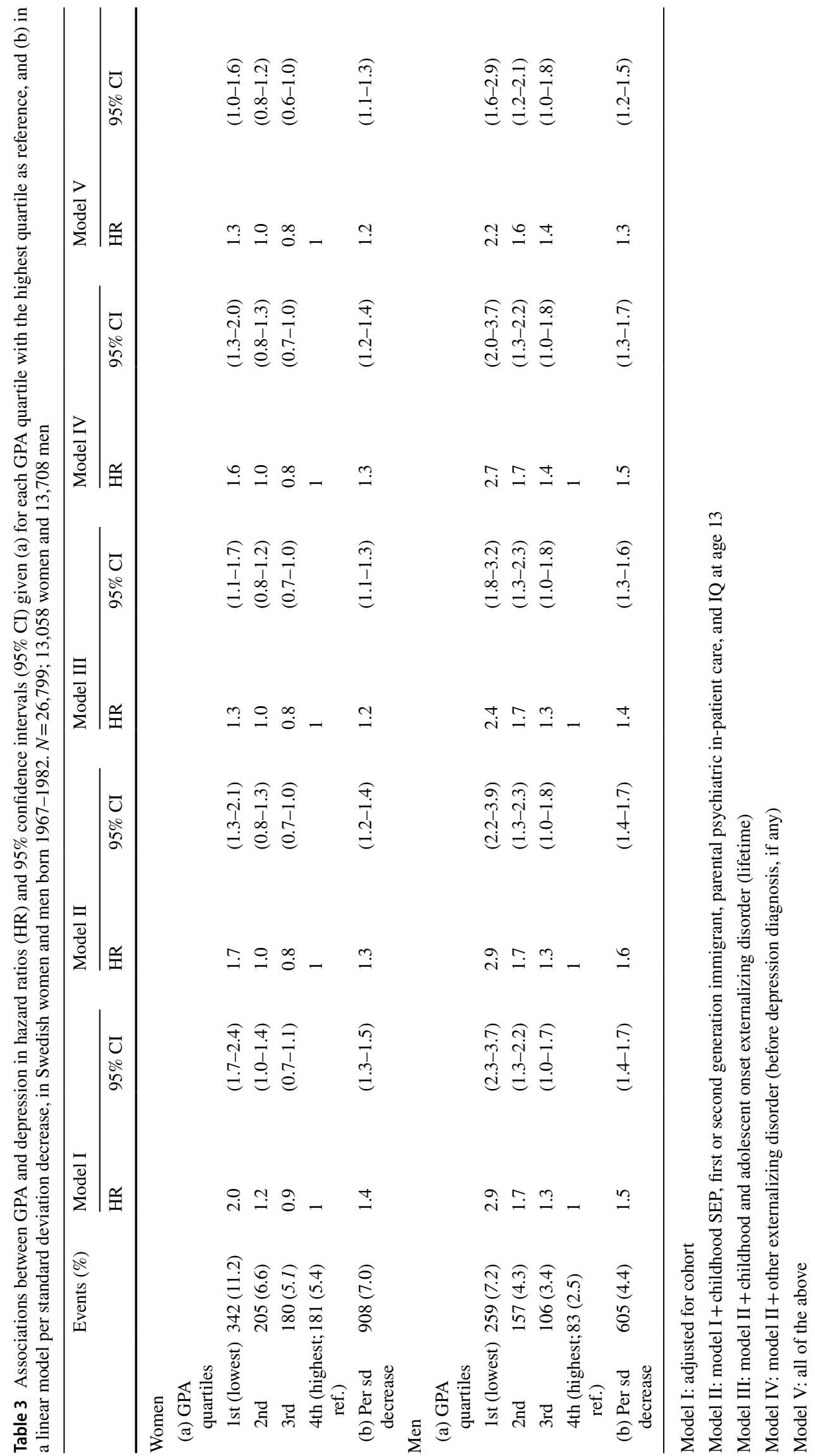


adulthood. There was a gradual increase in risk in men with lower grades, whereas in women only those with the poorest grades had a significantly higher risk. Adjusting for childhood SEP, immigrant background, psychiatric care among parents, and adolescent IQ did not attenuate the association substantially. By contrast, adjusting for early-onset externalizing disorders had a clear attenuating effect, although more so among women and among participants with the lowest school grades.

\section{Comparison with previous studies}

The associations of educational attainment and academic performance with psychiatric disorders overall, and with depression in particular, are well established $[1-4,11,17]$. However, there are few studies combining information on school grades and long-term follow-up of students into adulthood, which also limits the possibilities for comparison. Furthermore, we are not aware of any previous study with the opportunity to control for IQ, a key predictor of academic performance.

The participants' social background, as measured by the occupational social class of the household, did not confound the association in our study. Similarly, a recent study using Swedish large register-based data showed a clear association between poor academic performance in adolescence and depression in adulthood even when controlling for family members' educational attainment [3]. This measure likely correlates with IQ and other heritable traits, but is also an indicator of childhood socioeconomic position. Furthermore, previous studies of academic performance and psychiatric disorders also found a limited importance of social background, even when several indicators, such as parental education, single-parent household, receipt of public assistance and residential instability, were adjusted for $[2,19]$.

In a previous study of this cohort [27], we found a considerably stronger association of GPA with suicide attempt than we do with depression in the present study: the risk of suicide attempt was fivefold in women and men (combined) with GPA scores in the lowest quartile compared to the highest. The association did not change after adjustment for IQ measured at age 13, but the question of possible underlying explanations remains. Perhaps an important part of the answer is to be found in the externalizing disorders that we were able to include in the present study. Indeed, their explanatory effect on the association between academic performance and suicide attempt might be even greater, given that externalizing behaviours such as impulsivity and substance use are particularly strong risk factors for suicidal behaviour [28].

Our results, based on a larger set of cohorts with a longer follow-up period, extend and partly confirm the findings of Jonsson et al. [1]. These authors found an approximately doubled risk of a hospital diagnosis of depression between ages 18 and 30 in people with a GPA one SD lower than the average. Unlike our study, they also performed analyses of depression combined with a comorbid lifetime externalizing disorder as an outcome and found a four- and six-fold greater risk in people with a GPA one or two SDs below average, respectively. However, due to that particular construction of the outcome, it may have been externalizing disorders rather than depression that was strongly predicted by GPA.

\section{Interpretations}

Most likely, the association between lower school grades and higher risk of depression later in life is overlapping with the inverse association between social position and risk of depression previously established in the epidemiological literature [4]. In this way, the association between school grades and depression in the present study is also in line with the idea that "health gradients", also applied to mental health, at least partly have a psychosocial explanation related to status differentiation [29]. However, the increase in risk seemed to follow a gradient only among men. Among women, those scoring in the lowest quartile of grades were at increased risk while those scoring in the other three quartiles showed no notable differences in their risk of depression. Furthermore, early onset externalizing disorders seemed to be a factor contributing to the association. For the reasons outlined above, we might speculate that externalizing disorders also contribute to the even stronger association between academic performance and suicide attempt in adulthood that we found in a previous study of the same cohorts [27].

Previous research on trajectories between externalizing and internalizing problems and academic performance indicates that externalizing problems directly impact on school grades while internalizing problems are more often a consequence of the difficulties [7, 30, 31]. Systematic reviews of school dropout support these results [11,32]. Additionally, in the large Norwegian Young HUNT study internalizing problems even seemed to have a positive association with subsequent educational attainment, once externalizing co-morbidity had been taken into account [12]. In light of this, it seems likely that externalizing disorder with an early onset was an explanation of the association between GPA and subsequent risk of depression in our data.

In our analyses, externalizing disorders accounted for larger parts of the association between GPA and depression in women compared to men. This, in combination with the fact that the association was stronger among men, may hypothetically reflect different pathways linking academic performance to depression in women and men. For example, findings in a large US twin study suggested that depression is more related to interpersonal relations and personality in women while social-status-related factors 
such as occupational and financial stressors are of greater importance in men [15]. However, there appears to be limited epidemiological research on how men's and women's risks of depression may be affected by different social circumstances. Another possibility is that there are unmeasured factors behind the boys' lower performance [33] which are also associated with an increased risk of depression, including subclinical or other undiagnosed externalizing problems.

There are also factors other than externalizing disorders that may explain the association between academic performance and later risk of depression. For example, reading difficulties and other early problems in school [17], and household adversity and placement in foster care [2, $34]$ have adverse effects on academic performance. However, it should be noted that some of these problems may be expressed as externalizing behaviour or have a shared heritability with externalizing disorders [17, 35], and these, in turn, seem to account for most of the association between internalizing problems and poor performance in school, as shown in previous studies $[6,7,9,10,12]$. Unfortunately, we lack the data to explore such pathways in the present study.

\section{Implications}

Our findings highlight that students with poor performance in compulsory school have a higher risk of future mental health problems, far beyond school age. More attention, with a long-term perspective, should be given to this group, and the mechanisms need to be further investigated in future studies. Of note, there were considerably higher rates of later diagnosed externalizing disorders in participants with a poor GPA, and in particular diagnoses assumed to originate early in life (including genetically influenced disorders), such as ADHD and externalizing personality disorders, although they were diagnosed later in life in our study. Earlier detection of these conditions and adequate interventions in the school setting could perhaps mitigate adverse long-term consequences and increase future well-being for these individuals.

\section{Strengths and limitations}

The ETF cohorts consist of nationally representative samples of boys and girls who had IQ tests in the sixth grade of school (at 13 years of age). The participation rate was very high and there was virtually no selection bias. Data on academic performance, diagnoses of depression and externalizing disorders and background factors were obtained from national registers with high, long-term coverage and minimal attrition.

Nevertheless, there are limitations. First, no validations of the diagnoses of depression and externalizing disorders have been published, even though the patient registers have high coverage of psychiatric diagnoses [36]. On the other hand, these variables are the same as those investigated in some previous studies based on Swedish register data [1, 3]. Furthermore, the patient records only include disorders severe enough to be diagnosed and, therefore, the prevalence of depression is likely to be underestimated. Second, our measure of externalizing problems is also limited to more "severe" cases, and we have no information on disorders managed in primary care, or on un-diagnosed or subclinical problems. Thus, we are not able to estimate the full extent of externalizing disorders as an explanation for the association between school grades and subsequent depression and, therefore, there might still be a residual explanatory effect from externalizing disorders. In the current study, we are restricted to an examination of whether or not they are of importance. Third, people with a history of poor school results might be more likely to end up for assessment and be diagnosed with an externalizing disorder. Possibly, this could give rise to some exaggeration of the associations between GPA and these disorders. Our opportunity to directly investigate the effect of psychiatric problems before graduation from compulsory school was limited, however, since the only available information at that age consists of rare cases of in-patient care. Moreover, we cannot know how much of the explanatory effect of our category of childhoodonset and personality disorders on the association reflects to mediation rather than confounding even though they are assumed to be present early in life. Fourth, we had no data to investigate explanations by, for example, early school failure [17] or adverse circumstances such as household dysfunction or foster care placement $[2,34]$ on the link between GPA and future depression. Finally, we emphasize that this study was performed on a homogeneous population sample from a Scandinavian country with egalitarian educational policies, which may have to be considered when generalizing to other populations.

\section{Conclusions}

In this population of Swedish women and men, lower grades at the end of compulsory school were associated with a higher risk of diagnosed depression in adulthood. The increase in risk seemed to follow a gradient among men, while in women the risk was increased only in those with the lowest grades. Results from multivariable analyses indicate that externalizing disorders partly explain the association.

Funding This study was funded by Forte, grant numbers 2015-00057 and 2017-00173. 


\section{Compliance with ethical standards}

Conflict of interest SZ was supported by the NIHR Biomedical Research Centre at University Hospitals Bristol NHS Foundation Trust and the University of Bristol. The views expressed are those of the authors and not necessarily those of the NHS, NIHR or the Department of Health and Social Care. The other authors declare no conflict of interest.

Ethics statement The Regional Ethics Board in Stockholm, Sweden, approved this project. The data were linked and anonymized by Statistics Sweden before granting access for research.

Open Access This article is distributed under the terms of the Creative Commons Attribution 4.0 International License (http://creativeco mmons.org/licenses/by/4.0/), which permits unrestricted use, distribution, and reproduction in any medium, provided you give appropriate credit to the original author(s) and the source, provide a link to the Creative Commons license, and indicate if changes were made.

\section{References}

1. Jonsson U, Goodman A, von Knorring A-L, von Knorring L, Koupil I (2012) School performance and hospital admission due to unipolar depression: a three-generational study of social causation and social selection. Soc Psychiatry Psychiatr Epidemiol 47(10):1695-1706

2. Björkenstam E, Dalman C, Vinnerljung B, Weitoft GR, Walder DJ, Burstrom B (2015) Childhood household dysfunction, school performance and psychiatric care utilisation in young adults: a register study of 96,399 individuals in Stockholm County. J Epidemiol Community Health. https://doi.org/10.1136/jech-2015-20632 9

3. Kendler KS, Ohlsson H, Keefe RSE, Sundquist K, Sundquist J (2018) The joint impact of cognitive performance in adolescence and familial cognitive aptitude on risk for major psychiatric disorders: a delineation of four potential pathways to illness. Mol Psychiatry 23(4):1076-1083. https://doi.org/10.1038/mp.2017.78

4. Lorant V, Deliege D, Eaton W, Robert A, Philippot P, Ansseau M (2003) Socioeconomic inequalities in depression: a meta-analysis. Am J Epidemiol 157(2):98-112

5. Fletcher JM (2010) Adolescent depression and educational attainment: results using sibling fixed effects. Health Econ 19(7):855-871

6. Suldo SM, Gormley MJ, DuPaul GJ, Anderson-Butcher D (2014) The impact of school mental health on student and school-level academic outcomes: current status of the research and future directions. School Mental Health 6(2):84-98

7. Weeks M, Ploubidis GB, Cairney J, Wild TC, Naicker K, Colman I (2016) Developmental pathways linking childhood and adolescent internalizing, externalizing, academic competence, and adolescent depression. J Adolesc 51:30-40

8. Panayiotou M, Humphrey N (2018) Mental health difficulties and academic attainment: evidence for gender-specific developmental cascades in middle childhood. Dev Psychopathol 30(2):523-538

9. Van der Ende J, Verhulst FC, Tiemeier H (2016) The bidirectional pathways between internalizing and externalizing problems and academic performance from 6 to 18 years. Dev Psychopathol 28(3):855-867

10. Melkevik O, Nilsen W, Evensen M, Reneflot A, Mykletun A (2016) Internalizing disorders as risk factors for early school leaving: a systematic review. Adolesc Res Rev 1(3):245-255
11. Esch P, Bocquet V, Pull C, Couffignal S, Lehnert T, Graas M, Fond-Harmant L, Ansseau M (2014) The downward spiral of mental disorders and educational attainment: a systematic review on early school leaving. BMC Psychiatry 14(1):237

12. Evensen M, Lyngstad TH, Melkevik O, Mykletun A (2016) The role of internalizing and externalizing problems in adolescence for adult educational attainment: evidence from sibling comparisons using data from the Young HUNT Study. Eur Sociol Rev 32(5):552-566

13. Loth AK, Drabick DAG, Leibenluft E, Hulvershorn LA (2014) Do childhood externalizing disorders predict adult depression? A meta-analysis. J Abnorm Child Psychol 42(7):1103-1113. https:// doi.org/10.1007/s10802-014-9867-8

14. Ferrari AJ, Charlson FJ, Norman RE, Patten SB, Freedman G, Murray CJ, Vos T, Whiteford HA (2013) Burden of depressive disorders by country, sex, age, and year: findings from the global burden of disease study 2010. PLoS Med 10(11):e1001547

15. Kendler KS, Gardner CO (2014) Sex differences in the pathways to major depression: a study of opposite-sex twin pairs. AJ Psychiatry 171(4):426-435. https://doi.org/10.1176/appi.ajp.2013.13101 375

16. Merikangas KR, He J-p, Burstein M, Swanson SA, Avenevoli S, Cui L, Benjet C, Georgiades K, Swendsen J (2010) Lifetime prevalence of mental disorders in US adolescents: results from the National Comorbidity Survey Replication-Adolescent Supplement (NCS-A). J Am Acad Child Adolesc Psychiatry 49(10):980-989

17. Gustafsson J-E, Allodi Westling M, Åkerman A, Eriksson C, Eriksson L, Fischbein S, Granlund M, Gustafsson P, Ljungdahl S, Ogden T (2010) School, learning and mental health: a systematic review. The Royal Swedish Academy of Sciences, The Health Committee Stockholm

18. University of Gothenburg (2015) ETF-Cohort-sequential longitudinal databases evaluation through follow-up. University of Gothenburg. http://ips.gu.se/english/research/research_proje $\mathrm{cts} / \mathrm{ETF} /$ ?languageId $=100001 \&$ disableRedirect $=$ true \& retur $\mathrm{nUrl}=\mathrm{http} \% 3 \mathrm{~A} \% 2 \mathrm{~F} \% 2 \mathrm{Fips}$.gu.se $\% 2 \mathrm{Fforskning} \% 2 \mathrm{Fforskningspro}$ jekt\%2Fugu\%2F. Accessed 25 June 2018

19. MacCabe JH, Lambe MP, Cnattingius S, Sham PC, David AS, Reichenberg A, Murray RM, Hultman CM (2010) Excellent school performance at age 16 and risk of adult bipolar disorder: national cohort study. Br J Psychiatry 196(2):109-115

20. Gunnell D, Lofving S, Gustafsson JE, Allebeck P (2011) School performance and risk of suicide in early adulthood: follow-up of two national cohorts of Swedish schoolchildren. J Affect Disord 131(1-3):104-112. https://doi.org/10.1016/j.jad.2011.01.002

21. Härnqvist K (1968) Relative changes in intelligence from 13 to 18. II. Results. Scand J Psychol 9(1):65-82

22. Andersson L, Allebeck P, Gustafsson JE, Gunnell D (2008) Association of IQ scores and school achievement with suicide in a 40-year follow-up of a Swedish cohort. Acta Psychiatr Scand 118(2):99-105. https://doi.org/10.1111/j.1600-0447.2008.01171.x

23. Härnqvist K (1968) Relative changes in intelligence from 13 to 18. I. Background and methodology. Scand J Psychol 9(1):50-64

24. Kotov R, Krueger RF, Watson D, Achenbach TM, Althoff RR, Bagby RM, Brown TA, Carpenter WT, Caspi A, Clark LA, Eaton NR, Forbes MK, Forbush KT, Goldberg D, Hasin D, Hyman SE, Ivanova MY, Lynam DR, Markon K, Miller JD, Moffitt TE, Morey LC, Mullins-Sweatt SN, Ormel J, Patrick CJ, Regier DA, Rescorla L, Ruggero CJ, Samuel DB, Sellbom M, Simms LJ, Skodol AE, Slade T, South SC, Tackett JL, Waldman ID, Waszczuk MA, Widiger TA, Wright AGC, Zimmerman M (2017) The Hierarchical Taxonomy of Psychopathology (HiTOP): a dimensional alternative to traditional nosologies. J Abnorm Psychol 126(4):454477. https://doi.org/10.1037/abn0000258 
25. Krueger RF, Markon KE, Patrick CJ, Iacono WG (2005) Externalizing psychopathology in adulthood: a dimensional-spectrum conceptualization and its implications for DSM-V. J Abnorm Psychol 114(4):537-550. https://doi.org/10.1037/0021-843X.114.4.537

26. Grambsch PM, Therneau TM (1994) Proportional hazards tests and diagnostics based on weighted residuals. Biometrika 81(3):515-526

27. Sörberg Wallin A, Zeebari Z, Lager A, Gunnell D, Allebeck P, Falkstedt D (2018) Suicide attempt predicted by academic performance and childhood IQ: a cohort study of 26,000 children. Acta Psychiatr Scand 137(4):277-286

28. Gunnell D, Lewis G (2005) Studying suicide from the life course perspective: implications for prevention. Br J Psychiatry 187:206208. https://doi.org/10.1192/bjp.187.3.206

29. Pickett KE, Wilkinson RG (2010) Inequality: an underacknowledged source of mental illness and distress. RCP

30. Topitzes J, Godes O, Mersky JP, Ceglarek S, Reynolds AJ (2009) Educational success and adult health: findings from the Chicago Longitudinal Study. Prev Sci 10(2):175-195

31. Masten AS, Roisman GI, Long JD, Burt KB, Obradovic J, Riley JR, Boelcke-Stennes K, Tellegen A (2005) Developmental cascades: linking academic achievement and externalizing and internalizing symptoms over 20 years. Dev Psychol 41(5):733746. https://doi.org/10.1037/0012-1649.41.5.733

32. Melkevik O, Hauge LJ, Bendtsen P, Reneflot A, Mykletun A, Aaro LE (2016) Associations between delayed completion of high school and educational attainment and symptom levels of anxiety and depression in adulthood. BMC Psychiatry 16:64. https://doi. org/10.1186/s12888-016-0765-1

33. Gibb SJ, Fergusson DM, Horwood LJ (2008) Gender differences in educational achievement to age 25. Aust J Educ 52(1):63-80

34. Berlin M, Vinnerljung B, Hjern A (2011) School performance in primary school and psychosocial problems in young adulthood among care leavers from long term foster care. Child Youth Serv Rev 33(12):2489-2497

35. Salvatore JE, Meyers JL, Yan J, Aliev F, Lansford JE, Pettit GS, Bates JE, Dodge KA, Rose RJ, Pulkkinen L (2015) Intergenerational continuity in parents' and adolescents' externalizing problems: the role of life events and their interaction with GABRA2. J Abnorm Psychol 124(3):709

36. Ludvigsson JF, Andersson E, Ekbom A, Feychting M, Kim JL, Reuterwall C, Heurgren M, Olausson PO (2011) External review and validation of the Swedish national inpatient register. BMC Pub Health 11:450. https://doi.org/10.1186/1471-2458-11-450 